\title{
Etomidate infusion for severe Cushing's syndrome outside intensive care unit
}

\section{Agnieszka Łebek-Szatańska, Karolina M Nowak and Lucyna Papierska}

Department of Endocrinology, Centre of Postgraduate Medical Education, Bielanski Hospital, Warsaw, Poland
Correspondence should be addressed to A Łebek-Szatańska Email

agalebek@gmail.com
We have read with great pleasure and interest the article by Constantinescu et al. (1) about the usage of intravenous etomidate in the treatment of severe Cushing's syndrome (CS) and this letter provides further discussion of this theme. The authors compared the so-called 'low-dose' regimen applied in standard medical ward conditions to 'high-dose' regimen in intensive care unit (ICU) setting. In conclusion, they express an opinion that low-dose etomidate should be used more often in the treatment of severe hypercortisolaemia. To date, it has proved to be an effective, safe and available cortisol-lowering drug in severe cases. The ICU treatment could, however, be dedicated only to patients with Cushing's syndrome who need ventilation or organ-supporting therapies. It should be emphasized that although 'high-doses' of etomidate were associated with faster cortisol normalization, this was at the expense of hypocortisolism and subsequent glucocorticoid substitute therapy. The need for closer monitoring with the engagement of medical resources is non-negligible. Our experience strongly supports these observations. In the presentation of three cases from our department (2), we reported on the use of long-term low-dose etomidate treatment in patients with severe CS. Since this publication, another two patients - one with ectopic CS and one with metastatic adrenocortical carcinoma (ACC) - were treated using a similar protocol. On the contrary to Constantinescu et al. we used a loading bolus of $2.5 \mathrm{mg}$ of etomidate. Then, an infusion of $0.01-$ $0.02 \mathrm{mg} / \mathrm{kg} / \mathrm{h}(1-2 \mathrm{mg} / \mathrm{h})$ was carried on with no more boluses. These initial doses were uptitrated by $0.5 \mathrm{mg} / \mathrm{h}$ to a maximum of $4-5 \mathrm{mg} / \mathrm{h}(0.05-0.1 \mathrm{mg} / \mathrm{kg} / \mathrm{h})$ after weeks of treatment. Two out of the five patients were initially monitored in the ICU, but only for the first $24 \mathrm{~h}$. Two patients with metastatic ACC were administered etomidate twice - before and after ineffective causative therapy. No side effects of etomidate were observed in any of our patients. One patient was given hypnomidate and four were administered etomidate-lipuro, which is considered a better-tolerated form of this potent hypocortisolaemic agent. Another important aspect is the duration of etomidate therapy. In the study by Constantinescu et al. the treatment was continued for 9-20 days in a low-dose group. In most of our patients, etomidate therapy was carried out longer - up to 50-70 days. This prolonged etomidate infusion was also safe and sufficient to sustain stable, adequate serum cortisol concentration. Sepsis of bacterial origin and other hospital-acquired infections and complications were the main reason underlying the extended treatment period and delay in surgery.

To date, two patients from our department are still alive. In these rare clinical situations, etomidate was the only treatment option for life-threatening severe hypercortisolaemia. It is also the only drug for patients not able to take oral medications or when oral anti-steroid drugs are not available. To summarise, we fully support the authors' conclusion that low-dose etomidate is effective and well-tolerated. It can be successfully and safely administered in patients with severe Cushing's syndrome in standard ward conditions, ensuring the awareness of its use is widespread among clinicians outside the ICU.

Declaration of interest

The authors declare that there is no conflict of interest that could be perceived as prejudicing the impartiality of this letter. (c) 2020 European Society of Endocrinology Printed in Great Britain
Published by Bioscientifica Ltd. 


\section{Funding}

This research did not receive any specific grant from any funding agency in the public, commercial or not-for-profit sector.

\section{References}

1 Constantinescu SM, Driessens N, Lefebvre A, Furnica RM, Corvilain B $\&$ Maiter D. Etomidate infusion at low doses is an effective and safe treatment for severe Cushing's syndrome outside intensive care unit. European Journal of Endocrinology 2020183 161-167. (https://doi. org/10.1530/EJE-20-0380)

2 Łebek-Szatańska A, Nowak KM, Zgliczyński W, Baum E, Żyłka A \& Papierska L. Low-dose etomidate for the management of severe hypercortisolaemia in different clinical scenarios: a case series and review of the literature. Therapeutic Advances in Endocrinology and Metabolism 201910 2042018819825541. (https://doi. org/10.1177/2042018819825541)

Received 16 June 2020

Revised version received 25 August 2020

Accepted 17 September 2020 